\title{
Safety of adult medical male circumcision performed by non-physician clinicians in Kenya: a prospective cohort study
}

\author{
Vera Frajzyngier, ${ }^{a}$ George Odingo, ${ }^{b}$ Mark Barone, ${ }^{a}$ Paul Perchal, ${ }^{a}$ Melinda Pavin ${ }^{a}$
}

Trained, experienced nurses and clinical officers provided safe voluntary medical male circumcision (VMMC) in public health facilities in Nyanza Province, Kenya, as evidenced by the low $2 \%$ adverse event rate (most commonly, excess swelling). Task shifting for male circumcision can improve access to quality VMMC services.

\begin{abstract}
Background: Male circumcision reduces the risk of heterosexually acquired HIV infection in men by approximately $60 \%$. The Government of Kenya is rolling out voluntary medical male circumcision (VMMC) services, but struggles with health worker shortages, particularly with physician shortages.

Objective: To evaluate the safety of male circumcision performed by non-physician clinicians in Kenya.

Methods: Between December 2009 and December 2010, we conducted a prospective study of VMMC procedures performed by 15 nurses and 11 clinical officers, all trained to competence, in 11 public health facilities in Nyanza Province, Kenya. Providers reported surgical complications and adverse events (AEs), based on standardized definitions, immediately after the procedure and at 7 days and 60 days post-circumcision. We also assessed clients' satisfaction with the circumcision at 60 days.

Results: We recruited 2,244 men and boys, ages 13-54. The retention rate was high, with 2,192 participants (98\%) returning for the 7 -day follow-up visit and 1,845 (82\%) for the 60-day visit. There was no difference in rates of moderate and severe AEs between participants whose circumcision was performed by a nurse $(2.1 \%)$ or a clinical officer $(1.9 \%)$ at 7 days post-circumcision. The most common AE was excess swelling (1.1\%). Risk factors associated with an AE at 7 days post-circumcision included being employed and participant age $\geqslant 18$ years. Participants circumcised by a provider with $\geqslant 6$ years of professional experience were less likely to have an AE. Nearly all participants reported being satisfied with their circumcision at the 60-day follow-up visit.

Conclusions: Trained nurses and clinical officers provided safe VMMC in Nyanza Province, Kenya. AE rates in this study were similar to those reported in typical service-delivery settings. These results add to the current body of evidence suggesting that trained non-physicians can provide safe medical male circumcision, thereby facilitating increased availability and access to circumcision services.
\end{abstract}

\section{INTRODUCTION}

$I^{n}$ n 2007, based on results from 3 randomized controlled studies, ${ }^{1-3}$ the World Health Organization (WHO) and the Joint United Nations Programme on HIV/AIDS (UNAIDS) determined there was compelling evidence that male circumcision reduces the risk

\footnotetext{
a EngenderHealth, New York, NY, USA.

${ }^{b}$ EngenderHealth, Nairobi, Kenya.

Correspondence to Paul Perchal (pperchal@engenderhealth.org).
}

of heterosexually acquired HIV infection in men by approximately $60 \%{ }^{4,5}$ Later studies found that this protective effect against HIV is sustained over extended follow up (up to 6 years in the studies) ${ }^{6,7}$ As such, in countries with high HIV prevalence, a generalized heterosexual HIV epidemic, and low rates of male circumcision, WHO and UNAIDS recommend safe, voluntary circumcision for adult men as one important component of a comprehensive strategy to prevent $\mathrm{HIV}^{4}$ 


\section{Male circumcision reduces the risk of heterosexually acquired HIV infection in men by about $60 \%$.}

Nyanza Province in Kenya meets these criteria for voluntary medical male circumcision (VMMC) services. In 2008, the overall HIV prevalence rate in Kenya was $5 \%$, with approximately $83 \%$ of men circumcised, while in Nyanza Province, HIV prevalence was $12 \%$, with only $46 \%$ of men circumcised. ${ }^{8}$ Luos, an ethnic group of Kenya concentrated in Nyanza Province, ${ }^{9}$ had the highest rate of HIV (20\%), with only $22 \%$ of Luo men circumcised. ${ }^{8}$

In 2009, the Kenyan Ministry of Health rolled out a policy for adult male circumcision in response to the WHO/UNAIDS recommendation. The goal was to provide a framework to ensure safe, accessible, and sustainable male circumcision services. ${ }^{10,11}$

Although Kenya is committed to rolling out VMMC services, availability of health care providers, particularly physicians, is limited. ${ }^{10-12}$ Clinical officers were initially trained as the primary provider of male circumcision services. These are mid-level, non-physician clinicians, similar to physician assistants, whose preservice training focuses on clinical skills, often including minor surgeries. In 2009, the government approved nurses to also perform the procedure. ${ }^{13}$

Task shifting to include nurses as circumcision providers may be one short-term strategy for addressing the gap in human resources, especially in rural communities where there tend to be fewer clinical officers and physicians. Indeed, by the end of 2011, 10 of the 14 sub-Saharan African countries where scale up of VMMC services was deemed to be a priority had implemented task shifting, and 4 of these countries had explicit taskshifting policies. ${ }^{14}$

Ensuring safety of the male circumcision procedure is of critical importance, particularly when implemented as part of mass campaigns or when conducted by lower-level cadres. Adverse event $(\mathrm{AE})$ rates in controlled trials have ranged from $1.5 \%$ in Kisumu, Kenya, ${ }^{2}$ to $3.6 \%$ in Rakai, Uganda, ${ }^{3}$ and $3.8 \%$ in Orange Farm, South Africa. ${ }^{l}$ Adverse events reported in these studies included pain, ${ }^{1}$ bleeding, ${ }^{1,2}$ swelling, ${ }^{1,2}$ and infection, ${ }^{1-3}$ among others. A recent systematic review and meta-analysis of circumcisions conducted in the context of task shifting or task sharing found $\mathrm{AE}$ rates ranging from $0.70 \%$ (95\% confidence interval $[\mathrm{CI}]=0.44 \%-1.02 \%) \quad$ to $37.36 \% \quad(95 \%$ $\mathrm{CI}=27.54 \%-47.72 \%)$, with an overall pooled proportion of $2.31 \%$ (95\% CI $=1.46 \%-3.16 \%) .{ }^{15}$

This article reports findings from a study conducted by EngenderHealth, under the umbrella of the Male Circumcision Consortium, to assess the safety of circumcisions performed by nonphysician clinicians (clinical officers and nurses) as part of routine service provision, to better inform the Government of Kenya and the Ministry of Health regarding the feasibility of rolling out circumcision services by non-physicians. The Male Circumcision Consortium worked closely with the Kenyan Ministry of Health to help inform the provision and scale up of safe VMMC services.

The objectives of the study were:

1. To determine the proportion of men experiencing AEs at surgery and at 7 days and 60 days post-circumcision, by cadre

2. To evaluate risk factors associated with AEs post-circumcision

3. To assess client satisfaction with circumcision at 60 days post-surgery

\section{METHODS}

\section{Study Participants}

Between December 2009 and December 2010, men seeking circumcision at 11 health care facilities (6 hospitals, 4 health centers, and 1 dispensary) in Nyanza Province, Kenya, that provided integrated VMMC services were recruited for the study. Inclusion criteria included:

- 13-54 years old (reflecting ages of the boys and men seeking circumcision services at the sites)

- In good general health (per clinician assessment)

- Able to understand the study procedures and requirements

- Willing to return to the health care facility for follow up 7 days and 60 days after the procedure

- No contraindications to circumcision per the WHO male circumcision manual ${ }^{16}$

Informed consent was obtained from all participants in their local language prior to participation in the study. Minors (those under age 18) were asked to sign an assent form with consent provided by a parent.

\section{Study Procedures}

Circumcision procedures and all associated VMMC services were carried out in accordance with the "Policy on Male Circumcision in 
Kenya."10,11 All providers in this study were trained on male circumcision techniques, through a training program in Nyanza, based on the WHO/ UNAIDS "Manual for Male Circumcision Under Local Anaesthesia."16 The manual covers screening, preparation for surgery, surgical procedures, postoperative care, infection control, management of complications, and follow-up care. All providers were trained to competence in male circumcision per Kenya's policy on VMMC-that is, competency is achieved after following a formal training based on the WHO/UNAIDS manual and after performing 40 circumcisions under supervision; proficiency is achieved when a provider performs about 200 circumcisions.

The facilities involved in the study had adequate equipment and supplies as well space where confidential counseling and safe and hygienic procedures could be provided. Per Kenya's policy on male circumcision, in addition to the circumcision procedure, all study sites provided comprehensive HIV-prevention services, including:

- Behavior change communication and risk reduction counseling about safer sex practices

- Provision of male condoms and education about the need to use condoms consistently and correctly

- HIV testing and counseling

- Counseling and services for sexually transmitted infections (STIs)

- HIV care and treatment services, as appropriate

Providers were asked to complete a questionnaire about their demographic, educational, and professional profiles. Using standardized case report forms, trained research assistants and male circumcision providers collected data on clients' sociodemographic background, details of the preoperative clinical examination, procedures used during the circumcision, and surgical complications/AEs experienced immediately after the circumcision, as well as 7 days and 60 days following the procedure.

All clients were interviewed about satisfaction with their circumcision 7 days and 60 days following the procedure. A 7-day follow-up visit is standard in the Kenya VMMC program. A follow-up visit at 60 days was included in the study to evaluate AEs that may not have been apparent until healing was advanced or complete (such as torsion, excessive skin removal) and to gather information on client satisfaction after healing was complete.

Participants were given a modest travel allowance (the equivalent of approximately US\$3.00) at their 7-day and 60-day follow-up visits to enhance retention throughout the study.

The study was approved by the Institutional Review Board at the Kenya Medical Research Institute as well as the Protection of Human Subjects Committee at FHI 360.

\section{Study Measures}

We defined AEs based on standardized definitions outlined in the WHO male circumcision manual ${ }^{16}$ and listed on Kenya's VMMC Adverse Events reporting form, ${ }^{17}$ as well as based on definitions used by other researchers. ${ }^{2,3}$ Each post-discharge AE was graded on level of severity (mild, moderate, or severe) by the male circumcision provider examining the study participant. We then convened a panel of research, HIV, and clinical experts to review the AEs in order to avoid inclusion of events that were not considered causally associated with the circumcision procedure or were within normal limits. We report only moderate and severe AE rates because most mild AEs are generally considered within normal limits; this has become the standard for reporting clinical outcomes of male circumcision studies. ${ }^{18-22}$

We examined both provider- and clientrelated factors as possible risk factors associated with AEs.

Provider factors included:

- Cadre (clinical officer, nurse)

- Sex

- Years of professional experience $(<6, \geqslant 6)$

- Number of procedures conducted during the course of the study $(<100, \geqslant 100)$

- Duration of the surgery (continuous variable, as well as categorized: < 19 minutes, 19-23 minutes, $>23$ minutes)

Client factors included:

- Age (13-17 years, 18-54 years)

- Education (no secondary, at least some secondary)

- Marital status (single, married or living with partner)

- Employment status (employed, unemployed, student)

- Distance traveled to clinic ( $\leq 5 \mathrm{~km},>5 \mathrm{~km}$ )
All non-physicians in this study were trained on male circumcision techniques to the level of competence.

\section{Adverse event eports were based on standardized definitions.}


- Mode of transportation to the health facility (walk, car or bus, motorcycle or bicycle, other)

- HIV status (negative, positive)

At 7 days post-circumcision, we asked men about resumption of routine activities, and at 60 days post-circumcision, we assessed men's satisfaction with their circumcision through responses to the following interview questions:

- Would you recommend male circumcision to others?

- How satisfied are you with the circumcision? (very satisfied, somewhat satisfied, very dissatisfied, somewhat dissatisfied)

- How satisfied is your partner with the circumcision? (very satisfied, somewhat satisfied, very dissatisfied, somewhat dissatisfied)

\section{Statistical Analysis}

We calculated the proportion of men who experienced an $\mathrm{AE}$ associated with the circumcision prior to discharge and at 7 days and 60 days post-circumcision. We compared provider and client characteristics of those who presented with an $\mathrm{AE}$ at 7 days post-circumcision with those who did not by calculating odds ratios (ORs) and corresponding 95\% confidence intervals. Odds ratios were derived using generalized estimating equations (GEE) to account for clustering of client outcomes within facilities.

Variables eligible for inclusion in multivariate analysis were conceptually associated with risk of AEs and statistically associated $(P<.20)$ with the procedure in bivariate analysis. Adjusted ORs were also generated using GEE, accounting for clustering by facility. No AEs were reported when men were discharged following their circumcision, and few AEs were reported at 60 days post-circumcision, which precluded us from evaluating risk factors for $\mathrm{AE}$ at those points in time.

\section{RESULTS}

At 7 days
post-circumcision,
only $2.0 \%$ of the
men experienced
either moderate or
severe adverse
events.

\section{Provider Characteristics}

A total of 26 trained circumcision providers (15 nurses and 11 clinical officers) performed VMMC on study participants. The number of procedures performed by nurses ranged from 5 to 206, and by clinical officers, from 2 to 259 . All the clinical officers were male; 10 of the nurses were male and 5 female. On average, nurses were approximately 5 years older than clinical officers (average age of nurses, 39.3 years; clinical officers, 34.6 years).

Nurses worked, on average, about 4 more years in their profession than clinical officers (nurses, 13.7 years; clinical officers, 10.1 years). Somewhat before the study began, nurses' official scope of work did not include minor surgeries including male circumcision. However, they reported, on average, roughly the same number of years' experience performing minor surgeries as clinical officers (nurses, 10.1 years; clinical officers, 9.9 years) and male circumcisions (nurses, 4.3 years; clinical officers, 5.3 years).

In this study, clinical officers performed 818 (36\%) circumcisions and the nurses, 1,426 (64\%). On average, nurses conducted the surgery in slightly less time than clinical officers (mean, 22.4 minutes versus 24.5 minutes, respectively).

\section{Participant Characteristics}

The study recruited 2,244 men and boys. Most study participants were ethnically Luo (98\%) and were Christian (96\%) (Table 1). Mean age was 22.7 years. The majority $(72 \%)$ were single (not married, divorced, or widowed, or not living with a partner). Most men had at least some primary education (98\%), and over $70 \%$ had at least some secondary education. Most of the participants were either students (42\%) or employed (39\%). In general, the study participants lived relatively close to the health care facility where they had their circumcision performed, traveling on average about 5.5 kilometers, and 58\% walked to the clinic. About $6 \%$ reported they had HIV infection, and about 3\% reported they had a sexual partner (wife, primary partner, or any other partner) who had HIV infection. According to the participantreported data, among the men who had HIV infection, one-third had a discordant partner. Of the 2,244 men who were circumcised during the study, 2,192 (98\%) returned for the 7-day followup visit, and 1,845 (82\%) returned for the 60-day follow-up visit.

\section{Participants Experiencing an Adverse Event}

No study participant experienced surgical complications or immediate postoperative AEs.

At 7 days post-circumcision, $2.0 \%$ of the men experienced a moderate or severe $\mathrm{AE}$; the rates were similar between nurses and clinical officers (2.1\% vs. $1.9 \%$, respectively) (Table 2 ). The most common AE 7 days post-circumcision was excess 
TABLE 1. Sociodemographic Characteristics of Study Participants $(\mathrm{N}=2,244)$

\section{Characteristics}

Age, $y, n(\%)$

$13-17$

$517(23.0)$

$18-25$

1,137 (50.7)

26-35

$440(19.6)$

36-54

$150(6.7)$

$22.7(7.4)$

Age, $y$, mean (SD)

Ethnic group, n (\%)

Luo

$2,191(97.6)$

Other

$53(2.4)$

Religion, $\mathrm{n}(\%)$

Christian

Muslim

2,151 (95.9)

$18(0.8)$

Other

75 (3.3)

Marital status, $\mathrm{n}(\%)$

Single

$1,618(72.1)$

Married or living with partner

$606(27.0)$

Unknown

$20(0.9)$

Education, $n$ (\%)

No secondary education

$656(29.2)$

At least some secondary education

$1,588(70.8)$

Employment status, n (\%)

Unemployed

401 (17.8)

Student

950 (42.4)

Employed

$883(39.3)$

Unknown

$10(0.4)$

$5.5(6.5)$

Distance to clinic, km, mean (SD)

Mode of transportation to clinic, $n$ (\%)

Walking

$1,274(57.7)$

Car or bus

$389(17.6)$

Motorcycle or bicycle

$482(21.8)$

Other/unknown

$99(4.4)$

HIV positive, ${ }^{a} \mathrm{n}(\%)$

Self

$131(5.8)$

Partner (primary or other)

Abbreviations: SD, standard deviation.

a Self-reported by participants.

swelling (about 1\% among both nurses and clinical officers). There were no severe AEs, other than 2 cases of severe pain, as self-reported by men.

Men 18 years and older were significantly more likely than boys under 18 years old to experience an $\mathrm{AE}$ at 7 days post-circumcision. Specifically, compared with younger participants, men 18 years and older were significantly more likely to experience bleeding $(0.5 \%$ versus $0 \%)$ and swelling $(1.3 \%$ versus $0.2 \%)$ at the 7 -day follow-up visit.

At 60 days post-circumcision very few men $(0.2 \%)$ experienced moderate AEs, and no men had a severe AE (Table 2). There was no difference in AEs at 60 days between circumcisions performed by nurses and clinical officers.

At 7 days following their circumcision, $89 \%$ of the men reported they had resumed work, and $76 \%$ had resumed their leisure activities. Among those who had not resumed work activities by this time, $28 \%$ said they had too much pain or discomfort to do so. Among the men who had not resumed leisure activities by 7 days, 10\% reported they had not done so due to pain and discomfort.

\section{Factors Associated With Adverse Events}

In bivariate analyses, client age of 18 years and older was predictive of experiencing a moderate or severe $\mathrm{AE}$, while students were less likely to experience a moderate or severe AE. Provider professional experience 6 years or higher was also associated with a lower likelihood of a participant experiencing a moderate or severe $\mathrm{AE}$ $(P<.05)$ (Table 3$)$.

In multivariate analysis, after controlling for clustering by health facility, circumcisions performed by a provider with 6 or more years of professional experience were less likely to be associated with a moderate or severe AE at 7 days $(\mathrm{OR}=0.39,95 \% \mathrm{CI}=0.17-0.89 ; P<.05)$ (Table 3$)$. Circumcision clients who were employed $(\mathrm{OR}=2.41$, $95 \% \mathrm{CI}=1.06-5.5 \mathrm{l} ; P<.05)$ and 18 years and older $(\mathrm{OR}=3.75,95 \% \mathrm{CI}=1.92-7.33 ; P<.05)$ were more likely to experience a moderate or severe $\mathrm{AE}$ at 7 days post-circumcision.

\section{Client Satisfaction With the Circumcision}

At 60 days post-circumcision, over 99\% of study participants said they were satisfied; $99 \%$ reported their partner was satisfied; and over $99 \%$ said
At 60 days postcircumcision, very few men experienced moderate adverse events, and none had severe events.
Participants

circumcised by providers with 6 or more years of professional experience were less likely to have an adverse event. 
TABLE 2. Adverse Events at 7 Days and 60 Days Post-Circumcision, by Type of Provider and Severity

\begin{tabular}{|c|c|c|c|c|c|c|}
\hline \multirow[b]{2}{*}{ Adverse Event } & \multicolumn{3}{|c|}{7 days } & \multicolumn{3}{|c|}{60 days } \\
\hline & $\begin{array}{l}\text { Clinical Officer } \\
(n=807)\end{array}$ & $\begin{array}{c}\text { Nurse } \\
(n=1384)\end{array}$ & $\begin{array}{c}\text { Total } \\
(n=2191)\end{array}$ & $\begin{array}{c}\text { Clinical Officer } \\
(n=694)\end{array}$ & $\begin{array}{c}\text { Nurse } \\
(n=1151)\end{array}$ & $\begin{array}{c}\text { Total } \\
(n=1845)\end{array}$ \\
\hline Any moderate or severe $A E$ & 15 (1.9) & $29(2.1)$ & $44(2.0)$ & $2(0.29)$ & $1(0.09)$ & $3(0.16)$ \\
\hline \multicolumn{7}{|l|}{ Pain } \\
\hline Moderate & $\ldots$ & $\ldots$ & $\ldots$ & $\ldots$ & $1(0.07)$ & $1(0.05)$ \\
\hline Severe & $1(0.12)$ & $1(0.07)$ & $2(0.09)$ & $\ldots$ & $\ldots$ & $\ldots$ \\
\hline \multicolumn{7}{|l|}{ Infection } \\
\hline Moderate & $\ldots$ & $4(0.29)$ & $4(0.18)$ & $\ldots$ & $\ldots$ & $\ldots$ \\
\hline Severe & $\ldots$ & $\ldots$ & $\ldots$ & $\ldots$ & $\ldots$ & $\ldots$ \\
\hline \multicolumn{7}{|l|}{ Excess swelling } \\
\hline Moderate & $8(0.99)$ & $15(1.1)$ & $23(1.1)$ & $\ldots$ & $\ldots$ & $\ldots$ \\
\hline Severe & $\ldots$ & $\ldots$ & $\ldots$ & $\cdots$ & $\cdots$ & $\cdots$ \\
\hline \multicolumn{7}{|l|}{ Bleeding } \\
\hline Moderate & $1(0.12)$ & $\ldots$ & $1(0.05)$ & $\ldots$ & $\ldots$ & $\ldots$ \\
\hline Severe & $\ldots$ & $\ldots$ & $\ldots$ & $\ldots$ & $\ldots$ & $\ldots$ \\
\hline \multicolumn{7}{|l|}{ Problems with appearance } \\
\hline Moderate & $2(0.25)$ & $5(0.36)$ & $7(0.32)$ & $1(0.12)$ & $\ldots$ & $1(0.05)$ \\
\hline Severe & $\cdots$ & $\cdots$ & $\cdots$ & $\cdots$ & $\ldots$ & $\ldots$ \\
\hline \multicolumn{7}{|l|}{ Hematoma } \\
\hline Moderate & $2(0.25)$ & $1(0.07)$ & $3(0.14)$ & $\ldots$ & $\ldots$ & $\ldots$ \\
\hline Severe & $\ldots$ & $\ldots$ & $\ldots$ & $\ldots$ & $\ldots$ & $\ldots$ \\
\hline \multicolumn{7}{|l|}{ Delayed wound healing } \\
\hline Moderate & $\ldots$ & $3(0.22)$ & $3(0.14)$ & $\ldots$ & $\ldots$ & $\ldots$ \\
\hline Severe & $\ldots$ & $\ldots$ & $\ldots$ & $\ldots$ & $\ldots$ & $\ldots$ \\
\hline \multicolumn{7}{|l|}{ Injury to penis } \\
\hline Moderate & $\ldots$ & $\ldots$ & $\ldots$ & $1(0.12)$ & $\ldots$ & $1(0.05)$ \\
\hline Severe & $\ldots$ & $\ldots$ & $\ldots$ & $\cdots$ & $\cdots$ & $\cdots$ \\
\hline \multicolumn{7}{|l|}{ Insufficient skin removed } \\
\hline Moderate & $1(0.12)$ & $\ldots$ & $1(0.05)$ & $\ldots$ & $\ldots$ & $\ldots$ \\
\hline Severe & $\ldots$ & $\ldots$ & $\ldots$ & $\ldots$ & $\ldots$ & $\ldots$ \\
\hline
\end{tabular}


TABLE 3. Risk Factors for Moderate/Severe Adverse Events at 7 Days Post-Circumcision

No. of AEs/Total Unadjusted $\mathrm{OR}^{\mathrm{a}}(95 \% \mathrm{Cl})$

Adjusted $\mathrm{OR}^{\mathrm{b}}(95 \% \mathrm{Cl})$

\section{Provider Characteristics}

Sex

Male

Female

Cadre

Clinical officer

Nurse

Professional experience, $y$
$<6$
$21 / 808$
$13 / 1383$
$\geqslant 6$

$13 / 807$

$21 / 1384$

Reference

$1.04(0.42,2.60)$

Procedure duration, $\min$
$<19$
$3 / 526$
19-23
$13 / 689$
$>23$
$18 / 961$

No. of procedures conducted during the study

$$
\begin{aligned}
& <100 \\
& \geqslant 100
\end{aligned}
$$

$14 / 554$
$20 / 1637$

Reference

$0.64(0.31,1.32)$

\section{Client Characteristics}

Age, $y$

$$
\begin{aligned}
& 13-17 \\
& 18-54
\end{aligned}
$$$$
2 / 505
$$

$32 / 1686$

Reference

Education

No secondary education

At least some secondary education

Employment status

Unemployed

Employed

Student

Marital status

Single
Reference

$0.45(0.17,1.17)$

$0.22(0.01,5.9)$

$0.77(0.36,1.63)$

Reference
$4 / 395$

$21 / 867$

9/919

$22 / 1572$

$12 / 599$

$13 / 626$

$21 / 1550$

Reference

$0.63(0.35,1.12)$

Reference

$1.27(0.86,1.89)$

$0.65(0.43,0.97)$

Reference

$1.38(0.523 .62)$
Married or living with partner

$0.39^{c}(0.17,0.89)$

\section{$3.75^{\mathrm{c}}(1.92,7.33)$}

$0.61(0.34,1.11)$

$2.41^{\mathrm{c}}(1.06,5.51)$

$1.34(0.76,2.53)$ 
TABLE 3 (continued).

\begin{tabular}{|c|c|c|c|}
\hline & No. of AEs/Total & Unadjusted ORa $(95 \% \mathrm{Cl})$ & Adjusted $\mathrm{OR}^{\mathrm{b}}(95 \% \mathrm{Cl}$ \\
\hline \multicolumn{4}{|l|}{ Distance traveled, $\mathrm{km}$} \\
\hline$\leq 5$ & $16 / 1143$ & Reference & $\ldots$ \\
\hline$>5$ & $7 / 491$ & $1.05(0.46,2.38)$ & $\ldots$ \\
\hline \multicolumn{4}{|c|}{ Mode of transportation to the facility } \\
\hline Walking & $12 / 1246$ & Reference & $\ldots$ \\
\hline Car or bus & $10 / 379$ & $2.66(0.98,7.2)$ & $2.52(0.94,6.72)$ \\
\hline Motorcycle or bicycle & $9 / 474$ & $1.99(0.86,4.59)$ & $1.56(0.78,3.12)$ \\
\hline Other & $1 / 56$ & $2.38(0.62,9.11)$ & $1.56(0.37,6.54)$ \\
\hline \multicolumn{4}{|l|}{ HIV status } \\
\hline Negative & $26 / 1775$ & Reference & $\ldots$ \\
\hline Positive & $4 / 130$ & $2.09(0.65,6.65)$ & $\ldots$ \\
\hline
\end{tabular}

Nearly all men were satisfied with their circumcision.

\section{Adverse event rates for non-physicians in this study were similar to rates reported in typical service-delivery settings.}

they would recommend medical circumcision to a friend or family member.

\section{DISCUSSION}

The intent of this study was to evaluate the safety of trained non-physician cliniciansnurses and clinical officers-performing adult male circumcisions. These clinicians already had experience conducting minor surgeries and were trained on male circumcision techniques until they achieved competency. Men in this study experienced no immediate adverse outcomes associated with the circumcision or with postoperative procedures. Some did present with AEs at 7 days post-circumcision; fewer presented with AEs at 60 days post-circumcision. There was no difference in the rate of moderate and severe adverse events between participants who were circumcised by a nurse or a clinical officer.

Our findings of AE rates of $2.1 \%$ and $1.9 \%$, for nurses and clinical officers, respectively, are lower than moderate/severe $\mathrm{AE}$ rates (3.8\%) reported by Gray et al. in the clinical trial setting. ${ }^{3}$ AE rates in such controlled trials may be higher than those found in observational studies, due to heightened vigilance. However, our findings are also similar to those found in a more typical service-delivery setting with circumcisions performed by trained non-physicians; Herman-Roloff and colleagues reported an AE rate (moderate and severe) of $2.1 \%$ in the context of passive surveillance (routine clinical data reported by providers) and $7.5 \%$ in the context of active surveillance (outreach by research staff to identify and report events) in Nyanza Province, Kenya. ${ }^{19}$ While our detection of AEs was passive (that is, among participants returning to the clinic), $98 \%$ of participants returned for the 7-day follow-up visit. AE rates in this study were thus within an acceptable level compared with data from both the clinical-trial and servicedelivery settings.

Our findings are supported by similar studies evaluating the provision of circumcision by nonphysician providers. Buwembo and colleagues found no significant differences in moderate or severe $\mathrm{AE}$ rates between men whose circumcision was performed by physicians versus clinical officers $(1.5 \%$ and $0.68 \%$, respectively), after adjusting for other factors. ${ }^{20}$ Herman-Roloff and colleagues found no difference in the odds of experiencing an $\mathrm{AE}$ when providers of any type had reported previously performing at least 100 circumcisions. ${ }^{19}$ Others have also found that $\mathrm{AE}$ rates decreased as experience increased 
(based on number of male circumcisions performed). ${ }^{23-25}$ In our study, having conducted at least 100 circumcisions during the study period did not predict moderate or severe AEs; although participants circumcised by providers with less professional work experience $(<6$ years $)$ had increased risk of experiencing moderate or severe AEs.

We also investigated client-related risk factors for AEs, as some of these may be predictors or proxies for clients' behavior and risk postsurgery. Adult men, ages 18-54 years, were at higher risk of experiencing moderate or severe AEs than youth, ages 13-17 years. Adult men were more likely to experience bleeding than young men, which may not be surprising given differences in vascularization in pre-adolescents compared with adults. Adult men were also more likely to experience swelling (but not hematoma). From our data we cannot say why this occurred, and further investigation is warranted. Being employed was a risk factor for experiencing an AE. It is possible that employed men returned to work soon after the procedure, and in so doing disrupted the healing process.

\section{Limitations and Strengths of the Study}

Some limitations should be kept in mind. We did not have data on the number of circumcisions performed by each provider prior to participating in the study. Thus, we cannot evaluate provider proficiency prior to starting the study, although we know that providers were deemed competent at completion of their training. In addition, although we report AEs that we deemed to be causally associated with the circumcision, the rates we found may either overestimate or underestimate truly causal AE rates. We may have been underpowered to detect small significant differences, and results of our multivariate analysis are limited by wide confidence intervals and potentially unstable estimates. Finally, findings with regard to provider skill and experience must be interpreted with caution given the small number of providers who conducted circumcisions in the study. Our findings may not be generalizable to other service-delivery settings.

This study also has several strengths. Our retention rate at the 7-day follow-up visit was exceptionally high, and considerably higher than 7-day follow-up rates in the routine servicedelivery setting, which averaged $27.5 \%$ from 2008 to $2011,{ }^{26}$ decreasing the possibility that men returning for follow up were more likely to be those experiencing AEs. Further, as male circumcision is a key preventive measure for HIV, it is imperative to better understand risk factors associated with AEs after the procedure in order to make it as safe as possible. Information on such risk factors is currently limited in the literature. ${ }^{19,20}$ Our study contributes to a better understanding of these risk factors, and as such provides information that can strengthen male circumcision services. Our study also adds to the current body of evidence regarding task shifting for male circumcision in the routine servicedelivery setting, further suggesting that trained nurses and clinical officers can provide safe medical male circumcision, and thereby facilitate increased availability and access to circumcision services.

Acknowledgments: We wish to thank and acknowledge the men who participated in the study. We also thank the Homa Bay, Rachuonyo, Rongo, and Nyando District Health Departments and their male circumcision providers who made this study possible. We would also like to thank the Male Circumcision Consortium; the AIDS, Population, and Health Integrated Assistance (APHIA) II Nyanza Project funded by the U.S. Agency for International Development; Nicholas Muraguri and Peter Cherutich from the Kenya National AIDS/STI Control Programme; Jackson Kioko from the Kenya Ministry of Public Health and Sanitation; the Kenya Ministry of Medical Services; and the Nyanza Provincial Health Management team, for their collaboration and support. Furthermore, this work would not have been possible without the support and hard work of EngenderHealth research assistants, Rosemary Were and Evans Yanga. Other key contributors to this study from EngenderHealth were Feddis Mumba, Fredrick Ndede, and Jared Moguche. We also want to thank consultant Christie Jeon, for her analytic contribution on the project report. This research was made possible through a grant from the Bill \& Melinda Gates Foundation to the Male Circumcision Consortium, comprised of FHI 360, EngenderHealth, and the University of Illinois at Chicago, working with the Nyanza Reproductive Health Society.

Competing Interests: None declared.

\section{REFERENCES}

1. Auvert B, Taljaard D, Lagarde E, Sobngwi-Tambekou J, Sitta R, Puren A. Randomized, controlled intervention trial of male circumcision for reduction of HIV infection risk: the ANRS 1265 Trial. PLoS Med. 2005;2(11):e298. CrossRef. Medline

2. Bailey RC, Moses S, Parker CB, Agot K, Maclean I, Krieger JN, et al. Male circumcision for HIV prevention in young men in Kisumu, Kenya: a randomised controlled trial. Lancet. 2007;369(9562):643-656. CrossRef. Medline

3. Gray RH, Kigozi G, Serwadda D, Makumbi F, Watya S, Nalugoda F, et al. Male circumcision for HIV prevention in men in Rakai, Uganda: a randomised trial. Lancet. 2007;369(9562):657-666. CrossRef. Medline

4. World Health Organization (WHO), Joint United Nations Programme on UNAIDS. New data on male circumcision and HIV prevention: policy and programme implications: conclusions and recommendations. WHO/UNAIDS Technical Consultation on Male Circumcision and HIV Prevention: Research Implications for Policy and Programming, Montreux, 6-8 March 2007. Geneva: WHO; 2007. Available from: http://libdoc.who.int/ publications/2007/9789241595988_eng.pdf 
5. World Health Organization (WHO), Joint United Nations Programme on HIV/AIDS (UNAIDS). WHO and UNAIDS announce recommendations from expert consultation on male circumcision for HIV prevention [online press release]. Paris: WHO; 2007 [cited 2013 Dec 11]. Available from: http://www. who.int/mediacentre/news/releases/2007/pr10/en/index.html

6. Mehta S, Moses S, Agot K, Odoyo-June E, Li H, Maclean I, et al. The long term efficacy of medical male circumcision against HIV acquisition. AIDS. 2013;27(18):2899-2907. CrossRef. Medline

7. Gray R, Kigozi G, Kong X, Ssempiija V, Makumbi F, Wattya S, et al. The effectiveness of male circumcision for HIV prevention and effects on risk behaviors in a posttrial follow-up study. AIDS 2012;26(5):609-615. CrossRef. Medline

8. Kenya National Bureau of Statistics (KNBS), ICF Macro. Kenya demographic and health survey 2008-09. Calverton (MD): KNBS; 2010. Available from: http://www.measuredhs.com/ pubs/pdf/FR229/FR229.pdf

9. Luo of Bhar El Ghazal [Internet]. Memphis (TN): Luo of Bhar El Ghazal. Luo in Africa; 2008 [cited 2013 Dec 11 ]; [about 5 screens]. Available from: http://jo-luo.synthasite.com/luo-in-africa.php

10. Ministry of Public Health and Sanitation (MOPHS) [Kenya] Kenya national strategy for voluntary medical male circumcision. Nairobi: MOPHS; 2009. Available from: http://nascop.or.ke/ library/VMMC/VMMC\%20Strategy.pdf

11. Ministry of Health (MOH) [Kenya]. Policy on male circumcision in Kenya. Nairobi: MOH; 2007.

12. Perchal $P$, Odingo $G$, Pavin $M$. Exploring the human resources for health landscape for adult male circumcision rollout in four districts in Nyanza Province, Kenya. New York: EngenderHealth; 2011. Available from: http://www.engenderhealth.org/files/ pubs/hiv-aids-stis/engenderhealth-mc-hrtna-report-final.pdf

13. Government of Kenya (GOK). Ministry of Medical Services circular on training programs on male circumcision for nurses. Nairobi: GOK; 2009.

14. World Health Organization (WHO). Progress in scale-up of male circumcision for HIV prevention in Eastern and Southern Africa: focus on service delivery. Geneva: WHO; 2011. Available from: http://whqlibdoc. who.int/publications/2011/ 9789241502511_eng.pdf

15. Ford N, Chu K, Mills EJ. Safety of task-shifting for male medical circumcision: a systematic review and meta-analysis. AIDS. 2012;26(5):559-566. CrossRef. Medline

16. World Health Organization (WHO), Joint United Nations Programme on HIV/AIDS (UNAIDS), JHPIEGO. Manual for male circumcision under local anaesthesia: version 3.1. Geneva:
WHO; 2009. Available from: http://www.who.int/hiv/pub/ malecircumcision/who_mc_local_anaesthesia.pdf

17. Ministry of Public Health and Sanitation (MOPHS) [Kenya], National AIDS and STI Control Programme [Kenya]. Voluntary medical male circumcision adverse events form. Nairobi: MOPHS; 2009.

18. Kigozi G, Gray RH, Wawer MJ, Serwadda D, Makumbi F, Watya $S$, et al. The safety of adult male circumcision in HIVinfected and uninfected men in Rakai, Uganda. PLoS Med. 2008;5(6):e1 16. CrossRef. Medline

19. Herman-Roloff A, Bailey RC, Agot K. Factors associated with the safety of voluntary medical male circumcision in Nyanza province, Kenya. Bull World Health Organ. 2012;90(10):773781. CrossRef. Medline

20. Buwembo DR, Musoke R, Kigozi G, Ssempiija V, Serwadda D, Makumbi $F$, et al. Evaluation of the safety and efficiency of the dorsal slit and sleeve methods of male circumcision provided by physicians and clinical officers in Rakai, Uganda. BJU Int. 2012;109(1):104-108. CrossRef. Medline

21. Barone MA, Awori QD, Li PS, Simba RO, Weaver MA, Okech $\mathrm{JO}$, et al. Randomized trial of the Shang Ring for adult male circumcision with removal at one to three weeks: delayed removal leads to detachment. J Acquir Immune Defic Syndr. 2012;60(3):e82-e89. CrossRef. Medline

22. Mutabazi V, Kaplan SA, Rwamasirabo E, Bitega JP, Ngeruka $M L$, Savio $D$, et al. One-arm, open-label, prospective, cohort field study to assess the safety and efficacy of the PrePex device for scale-up of nonsurgical circumcision when performed by nurses in resource-limited settings for HIV prevention. J Acquir Immune Defic Syndr. 2013;63(3):315-322. CrossRef. Medline

23. Krieger JN, Bailey RC, Opeya JC, Ayieko BO, Opiyo FA, Omondi $D$, et al. Adult male circumcision outcomes: experience in a developing country setting. Urol Int. 2007;78(3):235-240. CrossRef. Medline

24. Bowa K, Lukobo M. Male circumcision and HIV in Zambia. East and Central African Journal of Surgery. 2006;1 1(2):66-71. Available from: http://www.bioline.org.br/pdf?js06037

25. Kiggundu V, Watya S, Kigozi G, Serwadda D, Nalugoda F, Buwembo $D$, et al. The number of procedures required to achieve optimal competency with male circumcision: findings from a randomized trial in Rakai, Uganda. BJU Int. 2009;104(4):529532. CrossRef. Medline

26. Centers for Disease Control and Prevention (CDC). Progress in voluntary medical male circumcision service provision - Kenya, 2008-2011. MMWR Morb Mortal Wkly Rep. 2012;61(47):957-961. Medline

\section{Peer Reviewed}

\section{Received: 2013 Aug 9; Accepted: 2013 Nov 10; First Published Online: 2014 Jan 9}

Cite this article as: Frajzyngier V, Odingo G, Barone M, Perchal P, Pavin M. Safety of adult medical male circumcision performed by non-physician clinicians in Kenya: a prospective cohort study. Glob Health Sci Pract. 2014;2(1):93-102. http://dx.doi.org/10.9745/GHSP-D-13-00120

(C) Frajzyngier et al. This is an open-access article distributed under the terms of the Creative Commons Attribution License, which permits unrestricted use, distribution, and reproduction in any medium, provided the original author and source are properly cited. To view a copy of the license, visit http://creativecommons.org/licenses/by/3.0/ 